\title{
Theft prevention using wireless security system (WSS)
}

\begin{abstract}
This paper presents a developed RFID based theft prevention system such that luxurious belongings, such as laptops which are monitored from being stolen. Global systems mobile (GSM) module is added to provide a complementary system to feedback to the users. The laptop tag ID and its timer sensed from RFID reader are registered in the system server. When the connectivity is broken when the laptop is taken away by more than its allowable distance, an alarm system will be alerted from server. A short message alerting the owner will be sent via the GSM module within a short period of time. This integrated system of RFID and GSM modules form a robust wireless security system. This system can be improved by using Bluetooth pervasive technology such that it can be exploited easily since it is been embedded in most of the mobile devices.
\end{abstract}

Keyword: Theft prevention; Wireless network; Wireless security system 